\title{
Fruiting Body of Pleurotus Ostreatus Reduces Serum Glucose and Modifies Oxidative Stress in Type 2 Diabetic: Drosophila Melanogaster (Fruit-Fly)
}

\author{
Omale S. ${ }^{1, *}$, Aguiyi JC. ${ }^{1}$, Bukar BB. ${ }^{2}$, Ede SO. ${ }^{2}$, Amagon KI. ${ }^{2}$, Amagon L. ${ }^{2}$, Usman O. ${ }^{2}$, Chinello V. ${ }^{3}$, \\ Oshibanjo DO. ${ }^{4}$

\begin{abstract}
${ }^{1}$ Department of Pharmacology and Toxicology Faculty of Pharmaceutical Sciences/Africa Centre of Excellence in Phytomedicine Research and Development (ACEPRD), University of Jos, Nigeria

${ }^{2}$ Department of Pharmacology and Toxicology, Faculty of Pharmaceutical Sciences, University of Jos, Nigeria

${ }^{3}$ Molecular Laboratory Africa Centre of Excellence in Phytomedicine Research and Development, University of Jos, Nigeria ${ }^{4}$ Department of Animal Production, Faculty of Agriculture, University of Jos, Nigeria
\end{abstract}

Received May 29, 2020; Revised July 14, 2020; Accepted July 29, 2020

Copyright $\odot 2020$ by authors, all rights reserved. Authors agree that this article remains permanently open access under the terms of the Creative Commons Attribution License 4.0 International License

\begin{abstract}
Mushrooms, which possess medicinal properties, are also considered a good source of food and basic nutrients. Diabetic patients now use edible mushrooms as a source of low-calorie food. Mushrooms are used to treat and prevent diseases such as diabetes, obesity, heart disease, hyperacidity, cancer, hypertension and also act as immune modulators. In this study, the antidiabetic and antioxidant effects of the fruiting body of Pleurotus ostreatus (PO) in sucrose-induced type-2 diabetic Drosophila melanogaster was investigated. The fresh fruiting body of $\mathrm{PO}$ was obtained from the mushroom farm of the Africa Centre of Excellence in Phytomedicine Research and Development (ACEPRD) and dried with the aid of the ASPRE dryer. The aqueous extract of the dried powder was used for the anti-diabetic and survival assay. The fly homogenate was evaluated for circulating glucose, total thiol, acetylcholinesterase, catalase and glutathione-S-transferase. PO was observed to prolong $D$. melanogaster's survival time as more flies $(>50 \%)$ survived on the extract compared to control (47\%), after 28 days. There was a significant $(P<0.05)$ decrease in the circulating glucose of the treated flies compared with those that were untreated; while no statistical $(P>0.05)$ difference was observed between the metformin and PO treated groups. In the antioxidant study, an insignificant $(P>0.05)$ difference between the untreated and treated groups was observed. Catalase activity showed a significant $(P<0.05)$ difference between the diabetic untreated and PO treated groups. We conclude that the fruiting body of $P$. ostreatus possessed potent hypoglycemic activities in D. melanogaster induced type-2 diabetes, possibly linked to its antioxidant property.
\end{abstract}

Keywords Antioxidants, Drosophila melanogaster, Glucose, Homogenate, Hyperglycemia, Pleurotus ostreatus, Type-2 diabetes

\section{Introduction}

Mushrooms are succulent fruiting bodies of fungus that usually grow on topsoil, wood as their food sources. They are either edible or poisonous and can be cultivated or harvested from the wild for human consumption. There exist over 2000 species of mushroom in nature, with only about 25 species safe for human consumption [1]. Edible mushrooms are treasured worldwide because of their nutritional significance $[2,3,4]$ and medicinal value $[5,6]$. Increased consumption of mushrooms is pertinent due to its high protein and trace mineral content [1].

Ethnopharmacological uses of mushrooms include, for example, prevention of diseases such as diabetes, obesity, heart disease, hyperacidity, cancer, and hypertension [7]. Mushrooms have been reported for their antitumor [8], antiviral $[9,10]$, antithrombotic [11], antioxidant $[12,13]$ and immunomodulatory properties [14]. The therapeutic activity of medicinal mushrooms can be attributed to the presence of bioactive components like high molecular weight polysaccharides, proteins, and lipids, as well as several low molecular weight metabolites like lectins, lactones, terpenoids, alkaloids, sterols, and phenolic substances $[2,15]$.

Edible mushrooms are ideal low-calorie foods for diabetic patients, as they are known to contain meagre 
amounts of fats and cholesterol, low levels of carbohydrates, high content of proteins, vitamins and minerals [1,2]. The anti-diabetic activity of Lentinus edodes, an edible mushroom, has been demonstrated in alloxan-induced diabetic Swiss albino mice [16]. Pleurotus ostreatus, another edible mushroom, has been shown to significantly decrease systolic and diastolic blood pressure, as well as fasting plasma glucose with $\mathrm{HbA1c}$ in male volunteers [7]. The ethanolic extract of Pleurotus ostreatus has anti-diabetic effects on alloxan-induced diabetic rats [17]. Pleurotus ostreatus also exhibited hypoglycemic, hypolipidemic, and hypocholesterolemic activity in streptozotocin-induced diabetes in rats.

Diabetes mellitus (DM) is a chronic metabolic disorder of insulin production, insulin resistance or insensitivity characterized by sustained hyperglycemia with resultant long-term microvascular (neuropathy, retinopathy, and nephropathy) and macrovascular (coronary artery disease, cerebrovascular and cardiovascular diseases) complications [20]. There are three recognizable types of diabetes mellitus: Type I, which develops as a consequence of the failure of the pancreatic $\beta$-cells to produce insulin commonly in children and adolescents; Type 2, which occurs due to insulin resistance or insensitivity of cells of the body to the presence of insulin, while Gestational diabetes occurs during pregnancy [20]. The ultimate consequences of diabetes are reduced life expectancy, significant morbidity due to specific diabetes-related microvascular and macrovascular complications, along with the diminished quality of life.

Reactive Oxygen Species (ROS) and Reactive Nitrogen Species (RNS) are oxidants or reactive molecules produced in the body. Oxidative stress is the imbalance between oxidants and antioxidant mechanisms of the body and has been implicated in the pathophysiology of human disorders such as diabetes, high blood pressure, arthritis, and hyperlipidemia [18]. Researchers have clearly shown that mushrooms possess antioxidant properties that reduce the harmful effects of reactive molecules, thus contributing immensely to health $[2,19]$. In type 2 diabetes, hyperglycemia induces oxidative stress due to increased production of reactive oxygen species (ROS) and reactive nitrogen species (RNS), which stimulate the production of antioxidants by the body's defense system. Oxidative stress has been implicated in the cellular injury of hyperglycemia culminating in micro and macrovascular complications of diabetes [21].

Despite the effectiveness of insulin and other oral hypoglycemics like metformin, issues relating to their cost, side effects, and contraindications in renal/liver disease, congestive heart failure, and pregnancy [22], have led to the search for more effective and safer agents. Exploring the blood-glucose-lowering effect of agents from natural sources such as mushrooms have thus attracted a great deal of attention.

Drosophila melanogaster is a versatile model for studying diabetes as it provides a useful complement to mammalian models. The insulin-like receptor ( $\mathrm{InR}$ ) found in D. melanogaster performs similar functions to insulin in mammals [23]. Functional conservation of Drosophila insulin receptor and insulin-like peptides (DILP) in growth similar to mammals has been described [24]. The Drosophila model provides insights into the specific pathways of insulin resistance [25]. Conservation of the mechanisms of glucose homeostasis between Drosophila and mammals is well understood [26]. Drosophila melanogaster, therefore, is a suitable model to evaluate nutraceuticals with the potential for lowering blood glucose. In this study, the anti-diabetic effects of Pleurotus ostreatus, an edible mushroom, using the Drosophila melanogaster model was investigated.

\section{Materials and Methods}

\subsection{Collection and Preparation of Pleurotus ostreatus (PO) Fruiting Body}

The fresh and fruiting bodies of Pleurotus ostreatus (oyster mushrooms) were obtained from the mushroom research farm at the Africa Center of Excellence in Phytomedicine Research and Development (ACEPRD), University of Jos, Plateau State, Nigeria in August 2019. The plant material was cut and dried using the ASPRE dryer at a temperature of $60{ }^{\circ} \mathrm{C}$ for about 24 hours, blended into a fine powder, and then weighed. The dry powder (150 g) was macerated in $500 \mathrm{ml}$ of distilled water for 48 hours with intermittent shaking. The macerate was filtered and the filtrate was freeze-dried and reduced to a fine powder.

\subsection{Fly Stock and Culture}

Drosophila melanogaster (Harwich strain) was obtained from the Drosophila research laboratory of the Africa Centre of Excellence in Phytomedicine Research and Development (ACEPRD), University of Jos, Plateau State, Nigeria. The fly-stock was originally from the National Species Stock Centre (Bowling Green, OH, USA). All flies were maintained at a constant temperature of $25^{\circ} \mathrm{C}$ and $70 \%$ relative humidity with a 12 -hour light/dark clock cycle in vials containing standard fly food.

Young flies of 2-3 days old were collected under mild ice anaesthesia from stock vials and used for the study. All experiments were conducted following the internationally accepted principles for laboratory animal use and care as found in EEC directives of 1986; 86/609/EEC. 

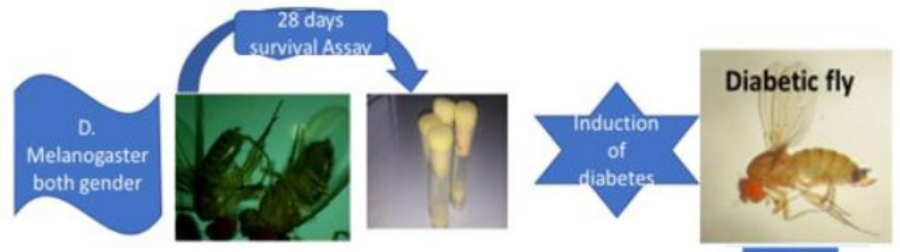

Glucose quantification
Total Thiol
Acetyl cholinesterase
activity
Catalase activity
Glutathione-S-
transferase
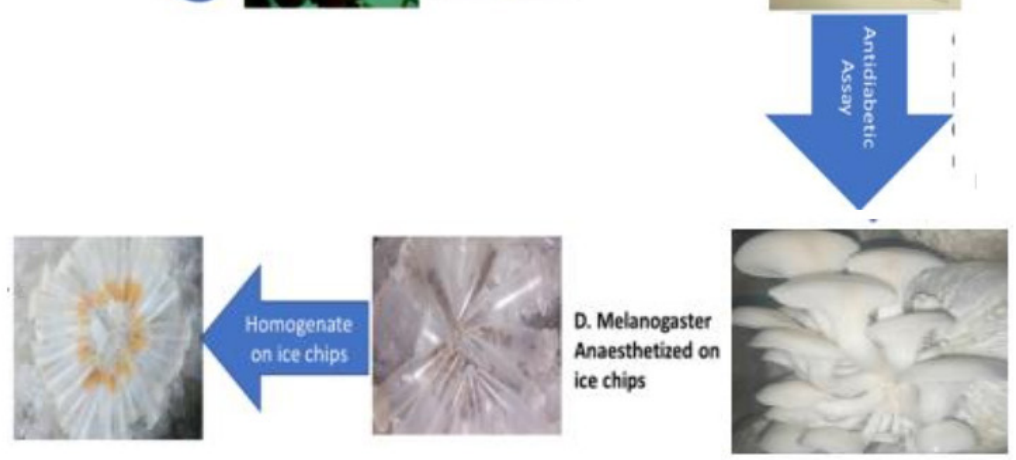

Metformin $16 \mathrm{mg} / 10 \mathrm{~g}$ diet PO $100 \mathrm{mg} / 10 \mathrm{~g}$ diet $250 \mathrm{mg} / 10 \mathrm{~g}$ diet $500 \mathrm{mg} / 10 \mathrm{~g}$ diet

Pleurotus ostreatus

Figure 1. Scheme of the Experimental Design

\subsection{Phytochemical Analysis}

The phytochemical analysis of the secondary metabolites was performed using standard methods [27].

\subsection{Survival Assay}

To determine the safety profile and appropriate concentrations of PO, $50 \mathrm{mg}, 100 \mathrm{mg}, 250 \mathrm{mg}$ and $500 \mathrm{mg}$ of PO were prepared in a $10 \mathrm{~g}$ fly food respectively and fed to the flies. Each group comprised five replicates of 50 flies each (both gender). The flies were flipped to newly prepared food containing the various concentrations every 3 days to maintain consistency of the diet. Fly mortality was scored daily for twenty-eight days.

\subsection{Induction of Diabetes in D. melanogaster}

We used standard methods described by Musselman and Morris $[28,29]$, who employed high sucrose content for ten days to induce type 2 diabetes in the $D$. melanogaster flies. Flies were observed daily for symptoms of diabetes such as delayed egg production, delayed emergence of first instar Larvae (L3), decreased body size for both larvae (L3) and adult flies, as well as decreased locomotor activity. The glucose concentration of the fly homogenate was quantified to ascertain hyperglycemia using the glucosidase method as described by the manufacturer.

\subsection{Antidiabetic Activities of Aqueous Extract of PO in D. melanogaster}

To investigate the anti-diabetic effects of PO in $D$. melanogaster, the methods described by Morris [29] were employed. Diabetic flies were placed on different concentrations of the aqueous extract of PO and $10 \mathrm{mg}$ metformin (oral hypoglycemic agent) respectively for 7 days, after which their glucose levels were determined. Six groups of 50 flies (both gender) in 5 replicates were treated as follows;

Control groups

Group I; Control 1 Non-diabetic flies on a normal fly diet

Group II; Control 2 Diabetic flies on normal fly diet

Group III; Diabetic flies on metformin $10 \mathrm{mg} / 10 \mathrm{~g}$ fly diet

Treated groups

Group IV; Diabetic flies on $100 \mathrm{mg} / 10 \mathrm{~g}$ fly diet

Group V; Diabetic flies on $250 \mathrm{mg} / 10 \mathrm{~g}$ fly diet

Group VI; Diabetic flies on $500 \mathrm{mg} / 10 \mathrm{~g}$ fly diet

\subsection{Locomotor Performance}

The locomotor performance of both the diabetic and treated flies was determined using the negative geotaxis method as described by Adedara et al and Ali et al [30,31].

\subsection{Preparation of Sample for Biochemical Assays}

The samples for biochemical assays were prepared on day 7 by anaesthetizing the flies on ice. The flies were then rinsed several times with cold potassium phosphate buffer

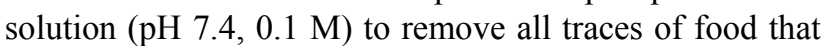
might be attached to the flies [29]. Each group was deposited into properly labeled pre-weighed eppendorf tubes according to the various concentrations. The corresponding weight of the flies was recorded and the phosphate buffer solution (PBS) at $10 \mathrm{uL}$ buffer per mg fly body weight was added followed by homogenization of the flies on ice chips. The homogenates were then centrifuged 
for 10 minutes at 4000 rotations per minute (rpm) in a Beckman Coulter Allegra X-I5R refrigerated centrifuge that had been prechilled to $4{ }^{\circ} \mathrm{C}$. The resulting supernatant was pipetted into the corresponding prelabelled eppendorf tubes and stored at $-18{ }^{\circ} \mathrm{C}$ until ready for use [30]. Subsequently, the supernatants were used for the determination of plasma glucose, total protein, total thiol (TSH), acetylcholinesterase

(AchE) Glutathione-S-Transferase (GST) and catalase (CAT) activities.

\subsection{Quantification of Glucose Level}

Randox Glu-Pap glucose oxidase assay kit was used in the determination of the glucose level of the samples. The assay was performed according to the manufacturer's protocol. The samples were diluted in 1:6 with PBS and mixed with the glucose oxidase reagents and incubated for 25 minutes at $25{ }^{\circ} \mathrm{C}$ and read at $540 \mathrm{~nm}$ using a spectrophotometer (Thermo Fisher Scientific).

\subsection{Quantification of Total Protein}

The protein concentrations of the various samples were determined using the Bradford method [32]. This was carried out using the Randox protein assay kit according to the manufacturer's protocol. The reagents were mixed and incubated for 30 minutes at $25{ }^{\circ} \mathrm{C}$, and the absorbance measured at $546 \mathrm{~nm}$ using a spectrophotometer (Thermo Fisher Scientific). The standard curve was determined by plotting the absorbance against concentration and the standard equation $(\mathrm{y}=\mathrm{mx}+\mathrm{c})$ was derived for quantification of protein contents of each sample. The samples were also mixed with the reagents and incubated for 30 minutes at $25^{\circ} \mathrm{C}$, and the absorbance measured at $546 \mathrm{~nm}$ using a spectrophotometer (Thermo Fisher Scientific) and quantified using the standard curve.

\subsection{Determination of the Total Thiol (TSH) Level}

The total thiol level was assayed according to the method of Ellman as reported by Abolaji et al [33] with some modifications. The total reaction mixture of $600 \mu \mathrm{l}$ containing $25 \mu \mathrm{l}$ of the sample, $510 \mu \mathrm{l}$ potassium phosphate buffer (pH 7.4), $30 \mu \mathrm{l}$ DTNB, and $30 \mu \mathrm{l} \mathrm{GSH}$ was used. This was incubated for 30 minutes at $25{ }^{\circ} \mathrm{C}$ and the absorbance was read at $412 \mathrm{~nm}$. A GSH standard curve was prepared to extrapolate the total thiol content and the results were calculated per mg protein.

\subsection{Determination of Acetylcholinesterase (AchE) Activity}

Acetylcholinesterase activity was assayed using the method of Ellman as described by Abolaji et al [33] with some modifications. The assay mixture was made up of $285 \mu \mathrm{l}$ of distilled water, $180 \mu \mathrm{l}$ of potassium phosphate buffer (pH 7.4), $60 \mu \mathrm{l}$ of DTNB, $15 \mu \mathrm{l}$ of the sample, and 60 $\mu l$ acetylthiocholine. The reaction was monitored for $2 \mathrm{~min}$ (15 seconds intervals) at $412 \mathrm{~nm}$ using a spectrophotometer. The various data were calculated against blank and sample blank and the results were corrected with the protein content.

\subsection{Determination of Catalase (CAT) Activity}

Catalase activity was evaluated according to the method described by Abolaji et al [33] with slight modifications. Briefly, $92 \mu l$ of $30 \% \mathrm{H}_{2} \mathrm{O}_{2}$ was added to $25 \mathrm{ml}$ of $0.1 \mathrm{M}$ phosphate buffer ( $\mathrm{pH}$ 7.4) and the volume made up to 50 $\mathrm{ml}$. The total reaction mixture was made up of $590 \mu \mathrm{l}$ of $\mathrm{H}_{2} \mathrm{O}_{2}$ and $10 \mu l$ of the sample (1:6 dilution PBS). The rate of disappearance of $\mathrm{H}_{2} \mathrm{O}_{2}$ was read for 2 minutes (10 seconds interval) at $240 \mathrm{~nm}$.

\subsection{Determination of Glutathione-S- Transferase (GSH) Activity}

The determination of the GST content of the sample was performed according to the method described by Abolaji et al [33] with little modifications. Briefly, the assay reaction mixture was made up of $600 \mu 1$ of a solution containing (20 $\mu 1$ of $0.25 \mathrm{M}$ potassium phosphate buffer, $\mathrm{pH} 7.0$, with 2.5 $\mathrm{mM}$ of ethylenediaminetetraacetic acid (EDTA), $10 \mu \mathrm{l}$ of distilled water and $500 \mu \mathrm{l}$ of $0.1 \mathrm{M} \mathrm{GSH}$ at $25^{\circ} \mathrm{C}, 60 \mu \mathrm{l}$ of the sample (1:4 dilution), and $10 \mu \mathrm{l}$ of $25 \mathrm{mM}$ CDNB. The reaction was monitored for $2 \min (10$ seconds intervals) at $340 \mathrm{~nm}$.

\subsection{Statistical Analysis}

The various data were statistically analyzed using one-way ANOVA and multiple t-tests of Graph pad Prism version 7 , with results presented as mean \pm standard deviation. A $95 \%$ confidence interval was used to determine the statistical difference between the control and the treated and between groups.

\section{Results}

Table 1. Phytochemical Constituents of Aqueous Extract of the Fruiting body of Pleurotus ostreatus

\begin{tabular}{|c|c|}
\hline Constituents & Remarks \\
\hline Alkaloids & +++ \\
\hline Flavonoids & ++ \\
\hline Tannins & -- \\
\hline Steroids & -- \\
\hline Terpenes & -- \\
\hline Carbohydrate & +++ \\
\hline Anthraquinones & -- \\
\hline Cardiac glycosides & ++ \\
\hline Saponins & -- \\
\hline
\end{tabular}

KEY; Not present --, Sparingly present + , Moderately present ++ , highly present +++ 
Alkaloids and carbohydrates were highly present, while flavonoids and cardiac glycosides were moderately present. Tannins, steroids, terpenes, anthraquinones, and saponins were absent.

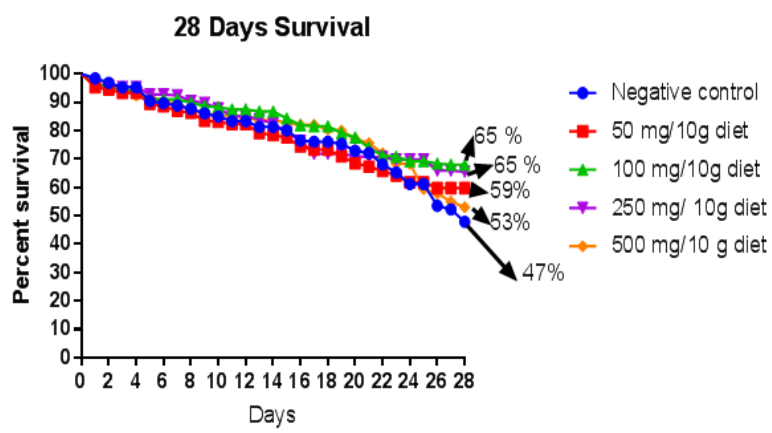

Figure 2. 28 Days Survival Assay of D. melanogaster Exposed to Pleurotus ostreatus

The extract of PO significantly increased $(P<0.05)$ the survival rate of $D$. melanogaster compared with the control.

\section{Baseline Serum Glucose}

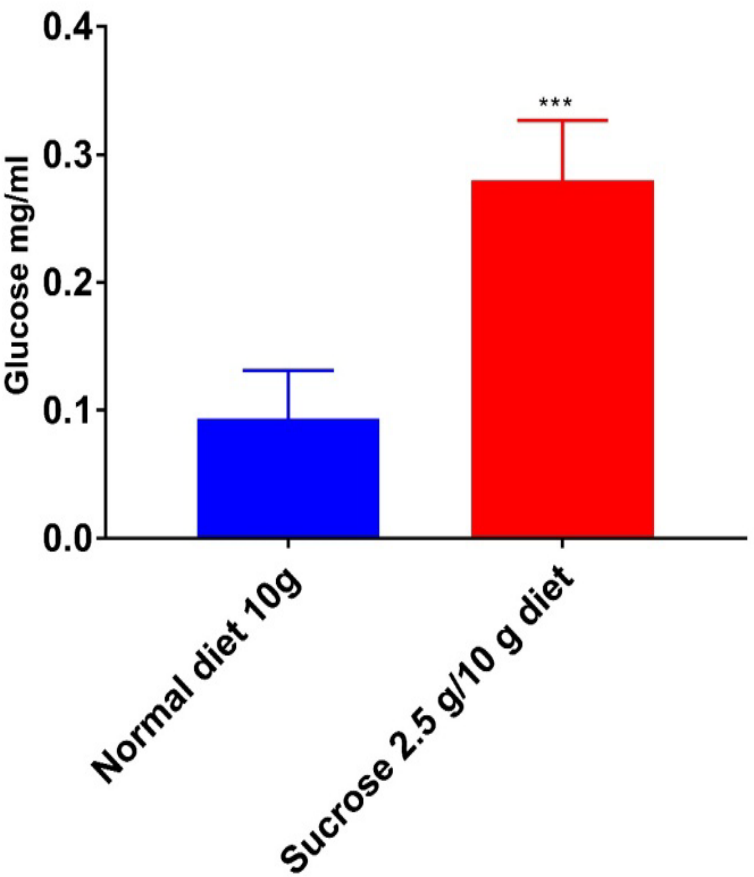

Figure 3. Baseline Serum Glucose of the Fly Homogenate

High sucrose content $(2.5 \mathrm{~g} / 10 \mathrm{~g}$ diet $)$ significantly increased $(P<0.05)$ the glucose content of the treated flies compared to the control with a $P=0.0001$.

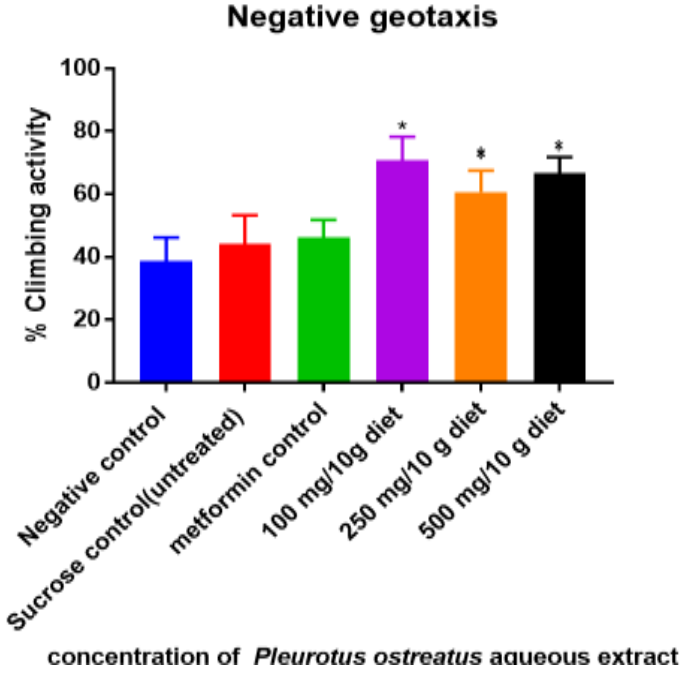

Figure 4. Locomotor Performance of Diabetic Flies Treated with Aqueous Extract of PO

Aqueous extract of $\mathrm{PO}$ significantly improves $(P<0.05)$ the locomotor performance of the diabetic flies with $\mathrm{P}$ $=0.003$. The highest performance was seen at the concentration of $100 \mathrm{mg} / 10 \mathrm{~g}$ diet.

\section{Circulating glucose}

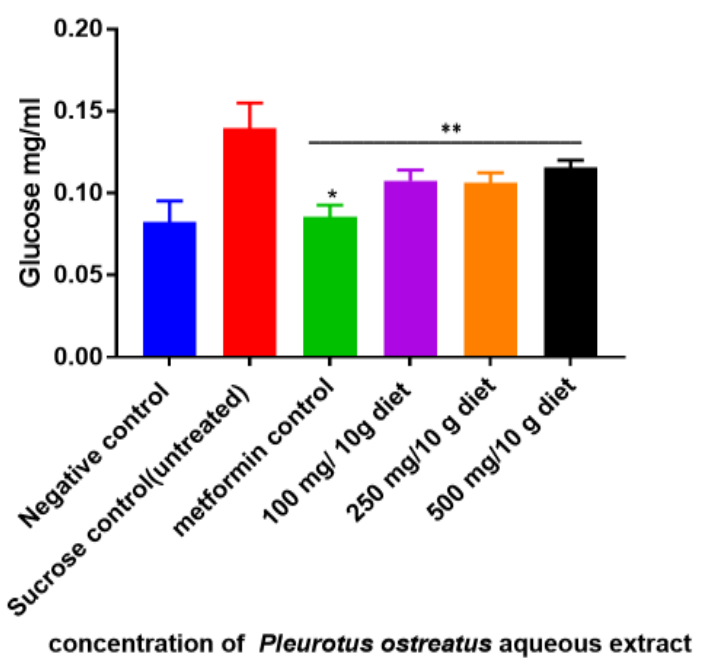

Figure 5. Glucose Level of Diabetic Flies Treated with Aqueous Extract of PO

The extract of Pleurotus ostreatus significantly $(P<0.05)$ decreased the circulating glucose of the diabetic flies compared to the diabetic untreated control group with $\mathrm{P}=0.009$. 


\section{Total Thiol}

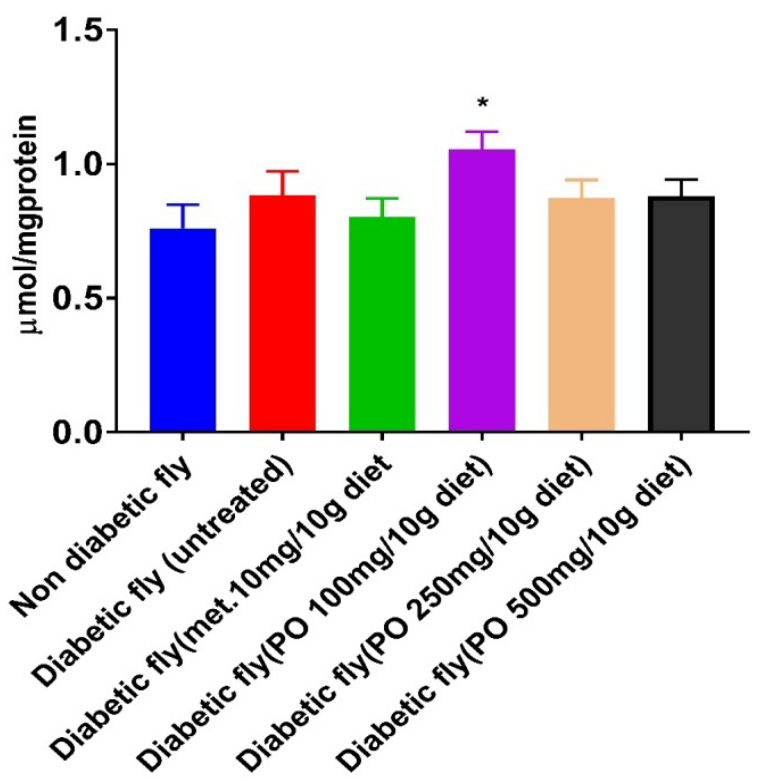

Figure 6. Total Thiol Levels of Diabetic Flies Treated with Aqueous Extract of PO

Only diabetic groups treated with $100 \mathrm{mg}$ extract of PO showed increased $(P<0.05)$ total thiol level compared with other groups including the metformin control group.

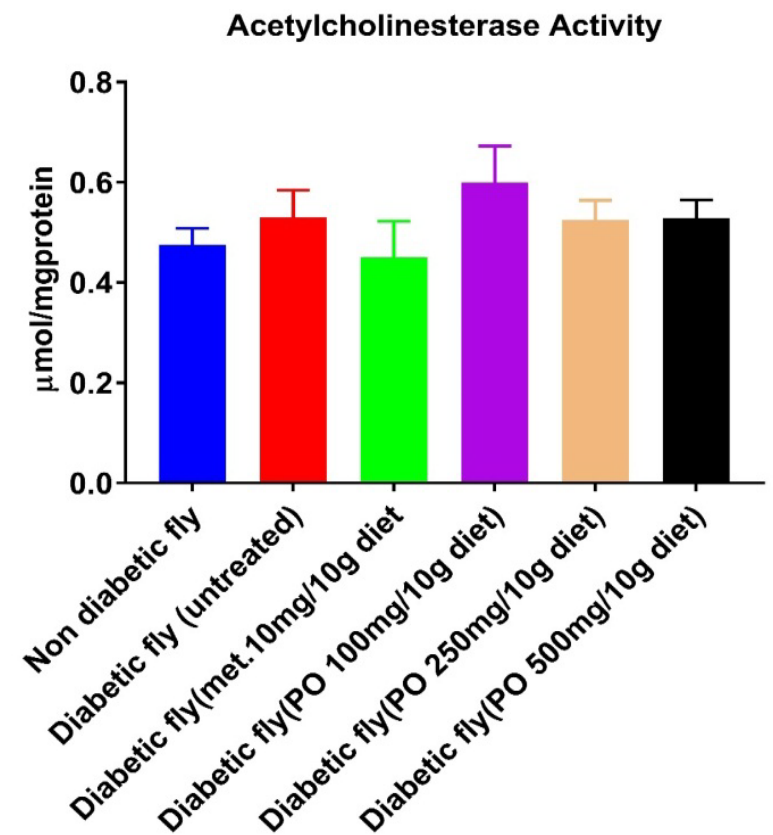

Figure 7. Acetylcholinesterase Activity of Diabetic Flies Treated with Aqueous Extract of PO

There was no significant difference $(P<0.05)$ between the AchE activity of all the groups.
CATALASE



Figure 8. Catalase Activity of Diabetic Flies Treated with Aqueous Extract of PO

There was a significant decrease $(P<0.05)$ in catalase activity between the diabetic treated and untreated groups with $\mathrm{P}=0.001$. There was no significant difference $(P>0.05)$ between the metformin, PO $250 \mathrm{mg} / 10 \mathrm{~g}$, PO $500 \mathrm{mg} / 10$ diet, and the non-diabetic flies.

\section{GST}

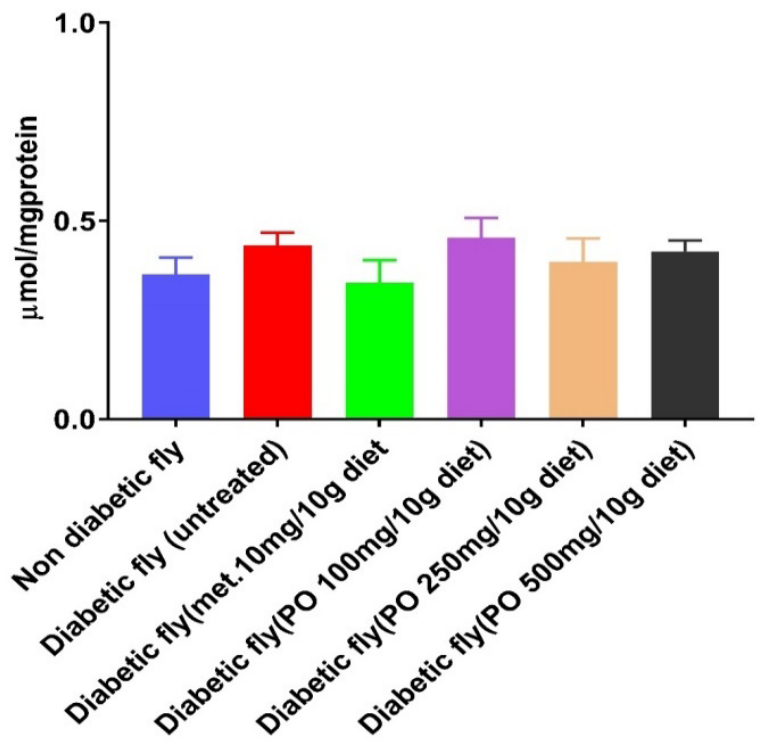

Figure 9. Glutathione-S-Transferase (GST) Activity of Diabetic Flies Treated with Aqueous Extract of PO

There was no significant difference $(P>0.05)$ between the GST activities of all the groups. 


\section{Discussion}

The phytochemical screening of the aqueous extract of Pleurotus ostreatus showed a high amount of alkaloids (Table 1). Plants rich in alkaloids have been shown to possess glucose-lowering effects [34], which is consistent with the results from this present study. The results of the 28 days survival assay showed the safety profile and the ability of the graded concentration of PO to increase lifespan in D. melanogaster as more flies ( $>50 \%)$ survived compared with control (47 \%) (Figure 2). Colpo et al. [35] observed similar findings in Drosophila treated with Ilex paraquariensis post feed on high-fat diet. The choice of 7 days treatment period was appropriate as greater than $95 \%$ of the fly population were alive on the seventh day [36].

The glycemic status of the diabetic and normoglycemic flies was determined on day 10 post-induction. The result showed sustained hyperglycemia in the diabetic group (Figure 3), thus D. melanogadter is an ideal model for type 2 diabetes mellitust (T2DM) because it exhibits sustained hyperglycemia post-induction [25,26,29]. The hyperglycemia was sustained throughout the experimental period in this present study.

The ameliorative effect of PO on the neuromuscular deficits of T2DM in D. melanogaster was investigated using the negative geotaxis method. There was significant improvement $(P<0.05)$ in the locomotor performance of the $\mathrm{PO}$ treated groups with $\mathrm{P}=0.003$ (Figure 4). T2DM has been understood to be accompanied by a host of pathologies, including obesity, cardiovascular disease, and fatty liver neuropathy, leading to decreased mobility [25]. Insulin resistance diabetes has been reported to have peripheral neuropathy symptoms such as increased muscle weakness and loss of reflexes, especially of the legs [37]. The increased locomotor activities observed in this present study may be attributed to the increase in acetylcholine at the neuromuscular junction (NMJ). This effect may be due to inhibition of acetylcholinesterase activity by PO or increased receptor sensitivity at the NMJ. The free radical formation has been implicated in Drosophila neuromuscular deficit [38]. The increase in locomotor activities observed in this present research can also be attributed to decreased free radical formation occasioned by the antioxidant effects of PO.

The circulating glucose of both non-diabetic and the diabetic treated groups was quantified using the glucosidase method. A significant $(P<0.05)$ decrease in the glucose level of the PO treated flies compared with the diabetic untreated and the metformin-treated control (Figure 5) was observed. Metformin (a biguanide), an oral hypoglycemics agent acting as an insulin sensitizer, is the baseline choice in the management of insulin-resistant diabetes. An insignificant $(P>0.05)$ difference was observed in the extent of the reduction in glucose level between metformin and the extract of PO. The extract of PO therefore, significantly reduced the hyperglycemic status in the diabetic Drosophila melanogaster. We speculate that the reduction in the circulating glucose observed in this study is a result of increased insulin sensitivity or insulin secretion. This finding is consistent with the increased locomotor activity in glucose metabolism [39].

Oxidative stress has been implicated in the development and complications of diabetes, obesity, cardiovascular diseases, Alzheimer's disease, and ageing [40,41]. Oxidation of components of animal cells can result in cellular damage leading to the development of various pathologies. On the other hand, antioxidants' response to oxidation is a physiological defensive mechanism that brings about cellular repair [25]. Increased levels of antioxidant biomarkers and antioxidant enzymes such as total thiol, glutathione-S-transferase, superoxide dismutase, hydrogen peroxide, catalase, and acetylcholinesterase in $D$. melanogaster during oxidative stress has been reported [42]. In this present study, the effect of the aqueous extract of PO on the level of physiological antioxidants in a diabetic fly was evaluated. The results showed no statistical $(P>0.05)$ difference in the total thiol level between the test and the control groups, except for PO 100 $\mathrm{mg} / 10 \mathrm{~g}$ diet. However, an increased level of the total thiol in the diabetic untreated group compared with the normoglycemic flies was observed (Figure 6). The decreased total thiol level in the treated group signifies antioxidant activities of PO [43]. There was also no statistical $(P>0.05)$ difference observed in the acetylcholinesterase activity of all the groups (Figure 7). Acetylcholinesterase (AchE) terminates the action of the physiological acetylcholine neurotransmitter. This result, therefore, suggests that the decreased locomotor performance observed in the diabetic flies may not be associated with changes in acetylcholine level but probably other mechanisms such as calcium channel or receptor sensitivity [24]. Our result showed increased catalase activity in the diabetic untreated while decreased activity was observed in metformin control, PO $250 \mathrm{mg}$, and 500 $\mathrm{mg} / 10 \mathrm{~g}$ diet respectively (Figure 8 ). There was no difference $(P>0.05)$ between the observed catalase activities of the normoglycemic, metformin, and PO 250 $\mathrm{mg}$ and $500 \mathrm{mg}$ groups respectively. Catalase is the physiological first line of defense to be drafted in oxidative insult [44]. Metformin has been demonstrated to ameliorate markers of oxidative stress such as total thiol, catalase, glutathione-S-transferase [4], resulting in low catalase activity consistent with our findings. We, therefore, postulate that aqueous extract of $P$. ostreatus might be exhibiting antioxidant effects similar to metformin. We observe no significant $(P>0.05)$ difference in the glutathione-S-transferase (GST) activity between the metformin, PO $250 \mathrm{mg}$, $500 \mathrm{mg} / 10 \mathrm{~g}$ diet, and normoglycemic groups. However, there was a slight increase in the GST activity of the hyperglycemic and PO 
$100 \mathrm{mg} / 10 \mathrm{~g} \operatorname{diet}($ Figure 9).

\section{Conclusions}

We conclude that aqueous extract of the fruiting bodies of $P$. ostreatus (an edible mushroom) possessed potent hypoglycemic activities in Type 2 diabetic $D$. melanogaster flies. The extract of the PO also demonstrates potent antioxidant activities as a possible mechanism of its antidiabetic effects and rescued the neuromuscular deficit in the diabetic $D$. melanogaster flies. These findings suggest that the fruiting body of Pleurotus ostreatus can be used as nutraceutical food supplements by diabetic patients to reduce circulating blood glucose. Furthermore, the antioxidant activities of PO have the potential for protecting the neuromuscular deficits in diabetes.

\section{Acknowledgements}

The authors are grateful to the staff of the Drosophila laboratory of Africa Centre of Excellence in Phytomedicine Research and Development (ACEPRD) for the use of their laboratory and equipment for this research.

\section{Funding Sources}

This research did not receive any specific grant from any funding agencies in the public commercial or not- forprofit sectors.

\section{Conflicts of Interest}

The authors declare that there exists no known conflicting interest in this present research and all sources have been duly acknowledged.

\section{REFERENCES}

[1] Barros, L., Baptista, P., Correia, D. M., Casal, S., Oliveira, B., \& Ferreira, I. C. F. R. Fatty acid and sugar compositions, and nutritional value of five wild edible mushrooms from Northeast Portugal. Food Chemistry, Vol.105, No.1, 140-145 (2007a)https://doi.org/10.1016/j.foodchem.2007.0 3.052

[2] Heleno, S. A., Ferreira, R. C., Antonio, A. L., Queiroz, M. J. R. P., Barros, L., \& Ferreira, I. C. F. R. Nutritional value, bioactive compounds and antioxidant properties of three edible mushrooms from Poland. Food Bioscience, Vol.11, 48-55 (2015).https://doi.org/10.1016/j.fbio.2015.04.006

[3] Manzi, P., Aguzzi, A., \& Pizzoferrato, L. Nutritional value of mushrooms widely consumed in Italy. Food Chemistry,
Vol.73, No.3, 321-325 (2001). https://doi.org/10.1016/S03 08-8146(00)00304-6

[4] Barros, L., Cruz, T., Baptista, P., Estevinho, L. M., \& Ferreira, I. C. F. R. Wild and commercial mushrooms as source of nutrients and nutraceuticals. Food and Chemical Toxicology, Vol.46, No.8, 2742-2747 (2008). https://doi.or g/10.1016/j.fct.2008.04.030

[5] Breene, W. M. Nutritional and Medicinal Value of Specialty Mushrooms. Vol.53, No.10, 883-894 (1990).

[6] Oyetayo, O. V. Medicinal uses of mushrooms in Nigeria: Towards full and sustainable exploitation. African Journal of Traditional, Complementary and Alternative Medicines, Vol. 8, No.3, 267-274 (2011). https://doi.org/10.4314/ajtca m.v8i3.65289

[7] Choudhury, M., Rahman, T., Kakon, A., Hoque, N., Akhtaruzzaman, M., Begum, M., Choudhuri, M., \& Hossain, M. Effects of Pleurotus ostreatus on Blood Pressure and Glycemic Status of Hypertensive Diabetic Male Volunteers. Bangladesh Journal of Medical Biochemistry, Vol.6, No.1, 5-10 (2013). https://doi.org/10.3329/bjmb.v6i1.13280

[8] Blagodatski, A., Yatsunskaya, M., \& Mikhailova, V. Medicinal mushrooms as an attractive new source of natural compounds for future cancer therapy. Vol.9, No.49, 29259-29274 (2018).

[9] Lindequist, U., Niedermeyer, T. H. J., \& Jülich, W. D. The pharmacological potential of mushrooms. Evidence-Based Complementary and Alternative Medicine, Vol. 2, No.3, 285-299 (2005). https://doi.org/10.1093/ecam/neh107

[10] Ellan, K., Thayan, R., Raman, J., Hidari, K. I. P. J., Ismail, N., \& Sabaratnam, V. Anti-viral activity of culinary and medicinal mushroom extracts against dengue virus serotype 2: An in-vitro study. BMC Complementary and Alternative Medicine, Vol.19, No.1, 1-12 (2019).https://doi.org/10.118 6/s12906-019-2629-y

[11] Islam, S., \& Uddin, P.K. In vitro Doses and Incubations Dependent Thrombolytic Potential Study of Edible Mushrooms Pleurotus ostreatus, Ganoderma lucidum and Lentinula edodes Available in Bangladesh. British Journal of Pharmaceutical Research, Vol.7,No.1, 44-51(2015). https://doi.org/10.9734/bjpr/2015/18227

[12] Boonsong, S., Klaypradit, W., \& Wilaipun, P. Antioxidant activities of extracts from five edible mushrooms using different extractants. Agriculture and Natural Resources, Vol.50 No.2, 89-97 (2016). https://doi.org/10.1016/j.anres. 2015.07.002

[13] Barros, L., Baptista, P., \& Ferreira, I. C. F. R. Effect of Lactarius piperatus fruiting body maturity stage on antioxidant activity measured by several biochemical assays. Food and ChemicalToxicology, Vol.45, No.9, 1731-1737(2007b).

https://doi.org/10.1016/j.fct.2007.03.006

[14] Guggenheim, A. G., Wright, K. M., \& Zwickey, H. L. Immune modulation from five major mushrooms: Application to integrative oncology. In Integrative Medicine Boulder press Vol. 13, No.1, pp. 32-44 (2014).

[15] Öztürk, M., Tel-Çayan, G., Muhammad, A., Terziołlu, P., \& Duru, M. E. Mushrooms: A source of exciting bioactive compounds. In Studies in Natural Products Chemistry,Vol. 
45, 363-456 (2015). https://doi.org/10.1016/B978-0-444-63 473-3.00010-1

[16] Islam, S., \& Uddin, P. K. Antihyperglycemic activity of edible mushroom, lentinus edodes in alloxan-induced diabetic Swiss albino mice. International Journal of Pharmaceutical and Clinical Research, Vol.6, No.2, 121-126 (2014)

[17] Johnny, I., \& Okon, J. Antidiabetic Effect of Pleurotus ostreatus (Jacq.ex Fr) Kumm.Mushroom on Alloxan-induced Diabetic Rat. Indian Journal of Pharmaceutical and Biological Research, Vo.1, No.1, 31-36 (2013). https://doi.org/10.30750/ijpbr.1.2.6

[18] Kurutas, E. B. The importance of antioxidants which play the role in cellular response against oxidative/nitrosative stress: Current state. Nutrition Journal, Vol.15, No.1, 1-22 (2016). https://doi.org/10.1186/s12937-016-0186-5

[19] Vamanu, E., Ene, M., Vamanu, A., Smarandache, D., Sârbu, I., Popa, O., Băbeanu, N., Niţă, S., \& Veaceslav, B. Antioxidant and antibacterial properties of the extracts from Pleurotus ostreatus EVFB1 and EVFB4. Romanian Biotechnological Letters, Vol.16, No.1, 40-46 (2011).

[20] Fowler, M. J. Microvascular and macrovascular complications of diabetes. Clinical Diabetes, Vo.29 No.3, 116-122 (2011). https://doi.org/10.2337/diaclin.29.3.116

[21] Fowler, M. J. Microvascular and macrovascular complications of diabetes. Clinical Diabetes, Vo.26, No.2, 77-82 (2008). https://doi.org/10.2337/diaclin.26.2.77

[22] Kavitha, N., De, S., \& Kanagasabai, S. Oral hypoglycemic agents in pregnancy: An update. Journal of Obstetrics and Gynecology of India, Vol.63, No2, 82-87 (2013). https://doi.org/10.1007/s13224-012-0312-z

[23] Graham, P. \& Pick, L. Drosophila as a Model for Diabetes and Diseases of Insulin Resistance. Current Topics in Developmental Biology Vol.121, 397- 419 (2017).

[24] Zhang, H., Liu, J., Li, C. R., Momen, B., Kohanski, R. A., \& Pick, L. Deletion of Drosophila insulin-like peptides causes growth defects and metabolic abnormalities. Proceedings of the National Academy of Sciences of the United States of America, Vol.106, No.46, 19617-19622 (2009). https://doi.org/10.1073/pnas.0905083106

[25] Musselman, L. P., Fink, J. L., Narzinski, K., Ramachandran, P. V., Hathiramani, S. S., Cagan, R. L., \& Baranski, T. J. A high-sugar diet produces obesity and insulin resistance in wild-type Drosophila.Disease Models and Mechanisms, Vol. 4, 842-849 (2011). https://doi.org/10.1242/dmm.007948

[26] Alfa, R. W., \& Kim, S. K. Using Drosophila to discover mechanisms underlying type 2 diabetes. DMM Disease Models and Mechanisms, Vol.9, No.4, 365-376 (2016). https://doi.org/10.1242/dmm.023887

[27] Visweswari, G., Christopher, R., \& Rajendra, W. Phytochemical Screening of Active Secondary Metabolites Present in Withania Somnifera Root: Role in Traditional Medicine. International Journal of Pharmaceutical Sciences And Research, Vol.4, No.43, 2770-2776 (2013). https://doi.org/10.13040/IJPSR.0975-8232.4(7)

[28] Musselman, L. P., \& Kühnlein, R. P. Drosophila as a model to study obesity and metabolic disease. In Journal of
Experimental Biology Vol. 121, 1-12(2018). https://doi.org/ $10.1242 /$ jeb. 163881

[29] Morris, S. N. S., Coogan, C., Chamseddin, K., Fernandez-Kim, S. O., Kolli, S., Keller, J. N., \& Bauer, J. H. Development of diet-induced insulin resistance in adult Drosophila melanogaster. Biochimica et Biophysica Acta Molecular Basis of Disease, Vol.1822, No.8, 1230-1237 (2012). https://doi.org/10.1016/j.bbadis.2012.04.012

[30] Adedara, I. A., Abolaji, A. O., Rocha, J. B. T., \& Farombi, E. O. Diphenyl Diselenide Protects Against Mortality, Locomotor Deficits and Oxidative Stress in Drosophila melanogaster Model of Manganese-Induced Neurotoxicity. Neurochemical Research, Vol.41, 1430-1438 (2016). https://doi.org/10.1007/s11064-016-1852-x

[31] Ali, Y. O., Escala, W., Ruan, K., \& Zhai, R. G. Assaying locomotor, learning, and memory deficits in Drosophila models of neurodegeneration. Journal of Visualized Experiments, Vol.49, 1-6 (2011). https://doi.org/10.3791/2 504

[32] Kruger, N.J. The Bradford Method for Protein Quantification. In: Walker J.M. (eds). The Protein Protocols Handbook. Humana Press (2002) https://doi.org/10.1385/15 9259-169-8:15

[33] Abolaji, A. O., Olaiya, C. O., Oluwadahunsi, O. J., \& Farombi, E. O. Dietary consumption of monosodium L-glutamate induces adaptive response and reduction in the life span of Drosophila melanogaster. Cell Biochemistry and Function, Vol.35, No.3, 164-170 (2017). https://doi.org/10. $1002 /$ cbf.3259

[34] Tiong, S. H., Looi, C. Y., Hazni, H., Arya, A., Paydar, M., Wong, W. F., Cheah, S. C., Mustafa, M. R., \& Awang, K. Antidiabetic and antioxidant properties of alkaloids from Catharanthus roseus (L.) G. Don. Molecules, Vol.18, No.8, 9770-9784 (2013). https://doi.org/10.3390/molecules18089 770

[35] Colpo, A.C., Lima, M.E., daRosa, H.S., Leal, A.P., Colares, C.C., Zago, A.C., Salgueiro, A.C.F., Bertelli, P.R., Minetto, L., Moura, S., Mandez, A.S.L., \& Folmer, V. Ilex paraquariensis extracts extend the lifespan of Drosophila melanogaster fed a high-fat diet. Brazilian Journal of medical and Biological Research, Vol51, No2, (2018) https://dx.doi.org/10.1016/j.freeradbiomed.2019.07.013

[36] Iorjiim, W. M., Omale, S., Etuh, M. A., Bagu, G. D., Ogwu, S. O., \& Gyang, S. S. EFV b -HAART Increases Mortality, Locomotor Deficits and Reduces Reproductive Capacity in Drosophila melanogaster. Journal of Advances in Biology and Biotechnology, Vol.23, No.1, 26-38 (2020). https://doi.org/10.9734/JABB/2020/v23i130136

[37] Bansal, V., Kalita, J., \& Misra, U. K. Diabetic neuropathy. Postgraduate Medical Journal, Vol.82 No.964, 95-100 (2006). https://doi.org/10.1136/pgmj.2005.036137

[38] Niveditha, S., Shivanandappa, T., Ramesh, S. Ameliorative Potential of Natural Antioxidants Against Paraquat-Induced Oxidative Stress and Locomotor Impairment in Drosophila melanogaster: A Comparative Study. Open Bioactive Compound Journal, Vol5 No1, 43-56 (2017)

[39] Giacco, F., \& Brownlee, M. (2010). Oxidative stress and diabetic complications. CirculationResearch,Vol.107,No.9, 1058-1070. 
https://doi.org/10.1161/CIRCRESAHA.110.223545

[40] Matschke, V., Theiss, C., \& Matschke, J. Oxidative stress: the lowest common denominator of multiple diseases. Neural Regeneration Research, Vol.14 No.2, 238-241 (2019).https://doi.org/10.4103/1673-5374.244780

[41] Hosamani, R., \& Muralidhara. Acute exposure of drosophila melanogaster to paraquat causes oxidative stress and mitochondrial dysfunction. Archives of Insect Biochemistry and Physiology, Vol.83No.1, 25-40 (2013). https://doi.org/ 10.1002/arch.21094

[42] Ighodaro, O. M., \& Akinloye, O. A. First line defence antioxidants-superoxide dismutase (SOD), catalase (CAT) and glutathione peroxidase (GPX): Their fundamental role in the entire antioxidant defence grid. Alexandria Journal of
Medicine, Vol.54 No.4, 287-293 (2018). https://doi.org/10. 1016/j.ajme.2017.09.001

[43] Iorjiim, W.M., Omale, S., Bagu, G.D., Gyang, S.S., Alemika, E.T., Etuh. M.A. Highly Active Antiretroviral Therapy Depletes Some Antioxidant Parameters and Increases Free Radical Generation in Drosophila melanogaster. Journal of Advances in Medical and Pharmaceutical Sciences, Vol22 No2,41-51 (2020)

[44] Esteghamati, A., Eskandari, D., Mirmiranpour, H., Noshad, S., Mousavizadeh, M., Hedayati, M., \& Nakhjavani, M. Effects of metformin on markers of oxidative stress and antioxidant reserve in patients with newly diagnosed type 2 diabetes: A randomized clinical trial. Clinical Nutrition, Vol.32 No.2, 179-185 (2013).https://doi.org/10.1016/j.clnu .2012 .08 .006 